\title{
STABILITY IMPROVEMENT OF DC POWER SYSTEMS IN AN ALL-ELECTRIC SHIP USING HYBRID SMES/BATTERY
}

\author{
P.AYUB KHAN ${ }^{1}$, P.SHAHIR ALI KHAN ${ }^{2}$, ATLA BHASKAR ${ }^{3}$ \\ 1, 2, 3-ANNAMACHARYA INSTITUTE OF TECHNOLOGY AND SCIENCES (AUTONOMOUS)- \\ RAJAMPET
}

\begin{abstract}
Energy storage systems are used in various applications to compensate for a fluctuating power demand. The combination of a prime mover and an energy storage device for reduction of fuel consumption has been successfully used in the automotive industry. As the capacity of all-electric ships (AESs) increases dramatically, the sudden changes in the system load may lead to serious problems, such as voltage fluctuations of the ship power grid, increased fuel consumption, and environmental emissions. In order to reduce the effects of system load fluctuations on system efficiency, and to maintain the bus voltage, we propose a hybrid energy storage system (HESS) for use in AESs. The HESS consists of two elements: a battery for high energy density storage and a superconducting magnetic energy storage (SMES) for high power density storage. A dynamic droop control is used to control charge/discharge prioritization. Maneuvering and pulse loads are the main sources of the sudden changes in AESs. There are several types of pulse loads, including electric weapons. These types of loads need large amounts of energy and high electrical power, which makes the HESS a promising power source. Using Simulink/MATLAB, we built a model of the AES power grid integrated with an SMES/battery to show its effectiveness in improving the quality of the power grid.

Index Terms-All-electric ship (AES), hybrid energy storage system (HESS), superconducting magnetic energy storage (SMES), pulse loads.
\end{abstract}

\section{I.INTRODUCTION}

Recent research has resulted in wide use of energy storages (ES) for several applicationssuch as electrical vehicles, diesel electric ships, or in relation with renewable energyproduction. There has also been an increasing attention around energy use in the oil and gasindustry. Offshore drilling rigs are mobile units that perform exploration to develop new oilor gas fields. Drilling operations require heavy power consuming electrical motors whichrepresent the main load on the vessels grid. The isolated grid of the drilling rig is usuallysupplied with diesel generators, in contrast to production platforms which can be poweredby gas turbines or HVDC transmission from land. Introducing an energy storage such as a capacitor bank may allow the motor loads to be operated more efficiently and may result inlower fuel consumption and emissions. The first objective of this project is to study how an energy storage system can improveefficiency of drilling operations for offshore drilling rigs and decide which requirements this sets for the energy storage. The specific power system studied is a DC-grid for jack-up rigs.The ES is intended to improve efficiency of a tripping operation, which involves lifting andlowering of the drill string and causes large variations in electrical load. An ES can smoothout load fluctuations on the diesel generators, allowing the motor loads to operate moreindependent from the diesel generators to speed up the tripping operation.

The studied load scenarios require an ES technology that can deliver rapidly increasing currents and high power. The second objective of this thesis is to investigate which EStechnology is best suited for the studied load scenario. Mainly two technologies are considered; electrolytic capacitors and super capacitors. Comparing these technologiesinvolves evaluating efficiency, energy- and power density.To solve the problem, the system is modelled in Simulink. The model itself is an importantproduct of this project and can be used for further studies of Energy Storage and DCgrids.Building a model of the system requires study of the load situation, energy storagetechnologies, DC-DC converters and marine DC-systems with diesel generators.

On the AES design, one of the most important features is the ramp-rate of the generators. The ramprate is the increased or decreased rate of the output power per minute and usually in MW/minute. The ramprate of ships' generators, such as gas turbine generators are in the range of 35 to $50 \mathrm{MW} /$ minute, whereas the pulse loads required a $100 \mathrm{MW} / \mathrm{second}$ ramp-rate, which is significantly higher than the ramp-rate of the generators. If the changes in the loads are faster than the ramp rate of the generators, unbalanced power between loads and generators occurs, which leads to instability in the power system. Because the ramp-rate of the ship's generators is not high enough to maintain the power demanded by electrical weapons, the need for an integrated power system (IPS) architecture is inevitable.In this paper, we propose the use of the superconducting magnetic energy storage (SMES)/battery HESS in AESs. Compared with super capacitors, flywheels, and other energy storage devices, SMES devices have higher power density, faster time response and unlimited charge and discharge life cycles. 
Because the battery has a relatively low power density, it cannot respond quickly in supplying the high transient current that is needed for the pulse loads. In this model, SMES works as a high power density device and a battery as the high energy density device. A dynamic droop control is used to coordinate the charge/discharge prioritization between the SMES and the battery. The ultimate goal of the HESS, based on dynamic droop control, is to supply the power demanded by the pulse loads and to maintain the main DC bus voltage within the targeted range.

\section{ELECTRIC SHIP TECHNOLOGY}

In 1878, the USS Trenton was built containing two propulsion systems. The ship had another new feature, an electric lighting system, which was the first U.S. Navy ship service power system. The size of the electric power system of the ship is dependent on the electric load demand. For instance, in sailing ships, the propulsion system provides power only for propulsion and not for the ship's service loads. Prior to and during World War II, in turboelectric ships, propulsion and ship service electric power were provided by separate prime movers. The first U.S. naval ship powered by electric motors in 1912 had two electrical systems: one for propulsion and the other for service loads. When the ship service load and propulsion load are provided power from the common generators, the power system is called an Integrated Power System (IPS), otherwise it is called a segregated power system. The segregated systems utilize separate generators for the ship service load and propulsion load. Figure 1 shows the comparison between a segregated power system and an integrated power system. From Figure 1, four geared turbines are used for propulsion system but three less powerful turbines are assigned for ship service loads. The problem with the segregated power system is that most of the produced power (around $80-100 \mathrm{MW}$ ) is available only for propulsion system. If higher power is required for the loads (example: pulsed load and radar load) except for propulsion load, it cannot be extracted from the propulsion turbines even if the propulsion system is not operating. To solve the problem with segregated power system, an IPS has been developed. Figure 1 shows that the IPS system uses fewer prime movers than the segregated power system and supply power to both propulsion load and service load. The IPS structure has been used on the DDG-1000 Zumwaltclass destroyer, the T-AKE-1 Lewis- and-Clark-class cargo ship, the currently suspended $\mathrm{CG}(\mathrm{X})$ next generation cruiser, the LHA-6 Makin-Island-class amphibious assault ship, the Flight III Virginia-class attack submarine, and the CVN-21 Gerald-Ford-class aircraft carrier. The U.S. Navy invested significantly in developing IPS structure between 1992 and 2007.
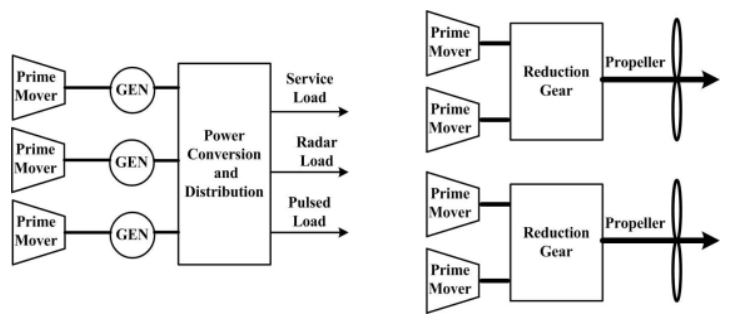

(a) A segregated power system.

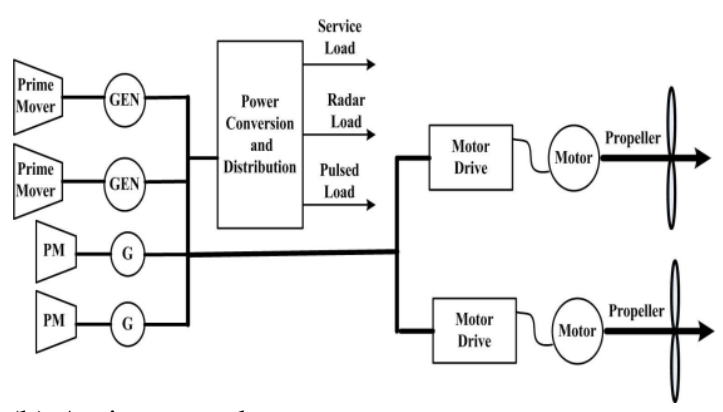

(b) An integrated power system.

Figure 1: Comparison between a segregated power system and an integrated power system.

A radical change of mechanical propulsion to electric propulsion produces a significant increase of electric power demand for the shipboard power system. The electric power demand is increased even more with the incorporation of railguns and lasers along with the regular ship service loads. Those pulsed loads demand high amplitude electric power (tens of MW range) within a very short time.

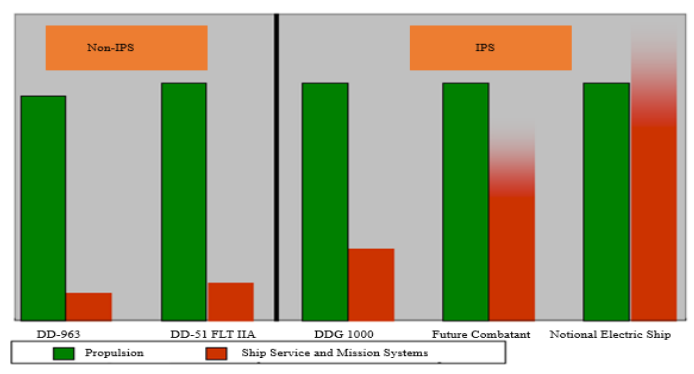

Figure 2: Comparison of Non-IPS and IPS power demand.

Figure 2 shows the projected propulsion load and ship service load for IPS and segregated structured based ship. It shows that ship service load is increasing because of incorporation pulsed load such as railguns and lasers. The modern ship design is migrating towards the IPS architecture with electric propulsion, advanced radar, and weapons system. In this IPS structure based power system, both the propulsion or ship service load receives power from the common source. The Office of Naval Research (ONR) has initiated a new program called Next Generation Integrated Power System (NGIPS) to provide direction for future IPS based electric ship development. The NGIPS technology development roadmap is shown in Figure 3 which has three phases. The first phase is medium voltage alternating current (MVAC) based configuration with 
voltage between $4 \mathrm{kV}$ to $13.8 \mathrm{kV}$ at $60 \mathrm{~Hz}$ frequency. This phase is already implemented in the DDG-1000 and the T-AKE-1. In order to reduce the size and weight of the components the second phase will be based on high frequency $\mathrm{AC}$ (HFAC) that uses same voltage range like MVAC ( $4 \mathrm{kV}$ to $13.8 \mathrm{kV} \mathrm{AC)}$, but that can operate higher than $60 \mathrm{~Hz}$ and lower than $400 \mathrm{~Hz}$. The final phase is based on MVDC with voltage range between $5 \mathrm{kV}$ to $20 \mathrm{kV}$.

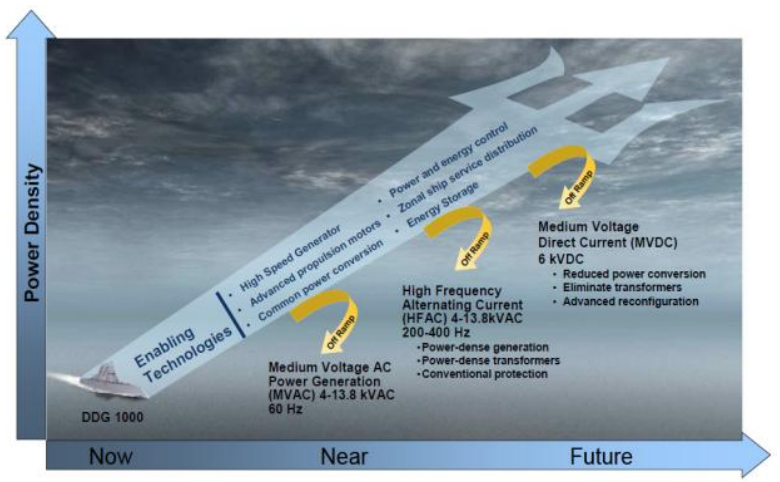

Figure 3: Projected development path for the IPS based structure for the shipboard power system.

\section{SYSTEM MODELING}

The MVDC power system on ships recommended was chosen to be the platform for testing the performance of the system and to assess the efficiency of the dynamic droop control. The simplified AES is shown in Fig. 4. The power on the ship is generated by two generators that meet the installed power demands. The two generators are connected to the main DC bus via AC/DC receivers. The two generators provide the power to the load evenly. Different types of loads are installed in the AES, including the propulsion load, ship service loads and pulse loads. In this model, the pulse loads represent the electrical weaponry system. The HESS is added to the system to supply the pulse loads. A dynamic droop control is used to arrange the charge/discharge in different energy storage devices.

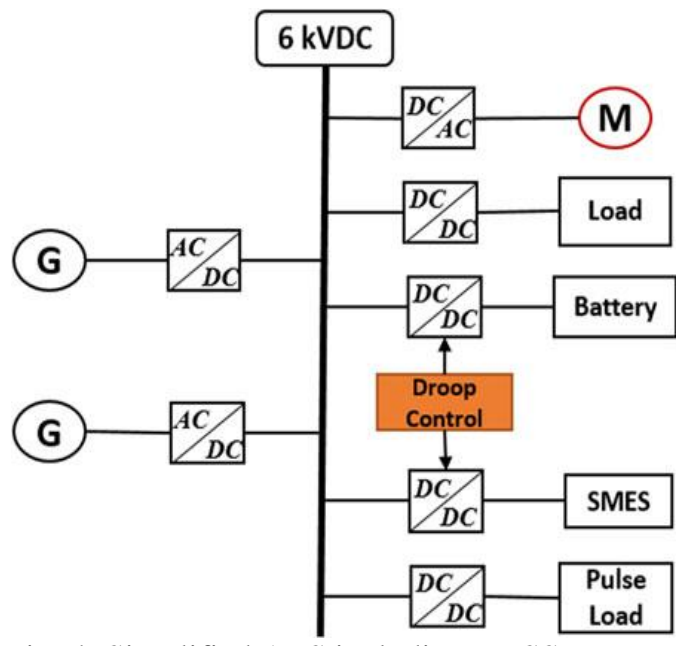

Fig. 4: Simplified AES including HESS.
Because the pulse load requires a high amount of power in a short period, and the ramp-rate of the generator cannot maintain it, the HESS is implemented in the system to supply this load. In this system, a synchronize motor is used as the electric propulsion motor. The propeller is connected directly to the synchronize motor. Because the ramp-rate of the generator is not high enough to supply and maintain the power demands of pulse loads, energy storage systems (ESS) have become essential to increase the amount of energy delivered within a short period. Two types of energy storage devices were chosen for this design: SMES and lithium-ion batteries. SMES is used as the high power density device to support the system during the transient periods. The SMES is controlled to deal with the short-term energy deficiency. Lithium-ion batteries are implemented in the AES to deal with longterm energy deficiency. Compared with other types of batteries, lithium-ion batteries have better energy density, low self-discharge and high efficiency. To protect the battery from overcharging and deep discharging, the state of charge (SOC) of the battery is regulated between $30 \%$ and $90 \%$. The design of the battery and SMES are based on the ship loads. There are three different types of load on the AES; 7MW static load (ship service load), 2 MW motor load and 5 MW pulse loads. During the normal operation, the ship service load and the motor load are applied to the system with a total power demand of 9 MW. During the pulse load periods, the demand rises by $5 \mathrm{MW}$ to a total of 14 MW. The battery capacity is calculated at $13.88 \mathrm{kWh}$ to cover the requirements of the pulse loads demand and to maintain the battery SOC constraints.

Because the SMES is more expensive than the Lithium-Ion battery in terms of energy density, the goal was to minimize the SMES size as much as possible whilst maintaining the voltage level at $6 \mathrm{kVDC}$. It was found that when the SMES size is reduced to $<500 \mathrm{~kJ}$, a voltage drop occurred in the main DC bus before the battery began discharging. The main goal of this work is to design a dynamic droop control system to operate the HESS at better efficiency during pulse load periods. Previous studies demonstrated the droop control used to share different power sources. This project proposes the use of HESS based on dynamic droop control to take advantage of the high power density of SMES and the high energy density of the battery in order to mitigate the effects of the pulse loads on the system's stability. The main principle of the control strategy is to generate different pulses in the SMES converter to control the charge and discharge of the SMES. The battery is controlled by a PI controller, which compares the main bus voltage and the voltage reference and considers the SOC of the battery. When the pulse load is added to the system, the SMES discharges immediately to feed the load and maintain the main bus voltage. Based on the dynamic droop control, the SMES discharge rate will decrease gradually to allow the battery to increase the discharge rate based on the pulses that are generated to 
the SMES and the battery. The main DC bus voltage is maintained within the required range (Vref (min) $<$ bus $<$ Vref $(\max ))$. According to the IEEE standard, the DC voltage tolerance limits should be $\pm 10 \%$. However, the tolerance limit was tightened to $\pm 3 \%$ in order to improve the system stability, as this was the main concern of this study. Vref (min) is $0.97 \mathrm{pu}$ of the nominal voltage, and Vref $(\max )$ is $1.03 \mathrm{pu}$ of the nominal voltage.

\section{SIMULATION RESULTS}

The simplified AES is modeled in the SimPowerSystems environment. The simulation results showed three different kinds of system behavior: without ESS, with battery only and with HESS.

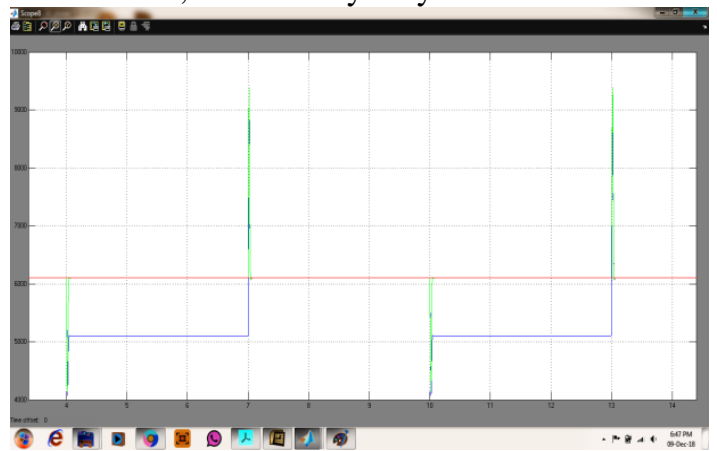

Fig 5: The DC bus voltage without ESS, battery only system and with HESS.

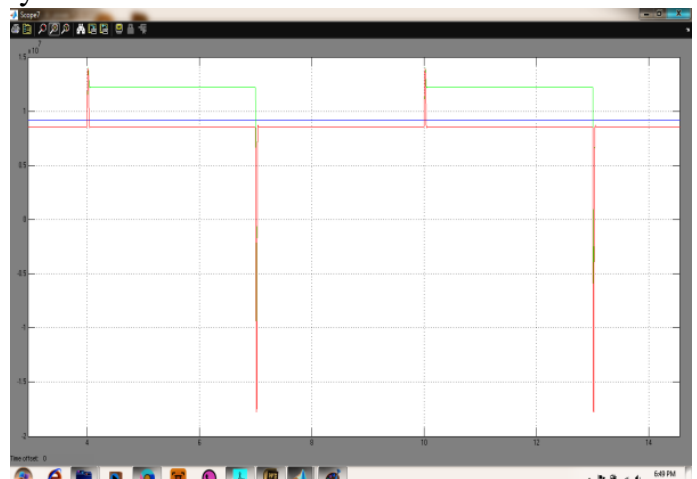

Fig 6: The total power generation without ESS, with battery only and with HESS.

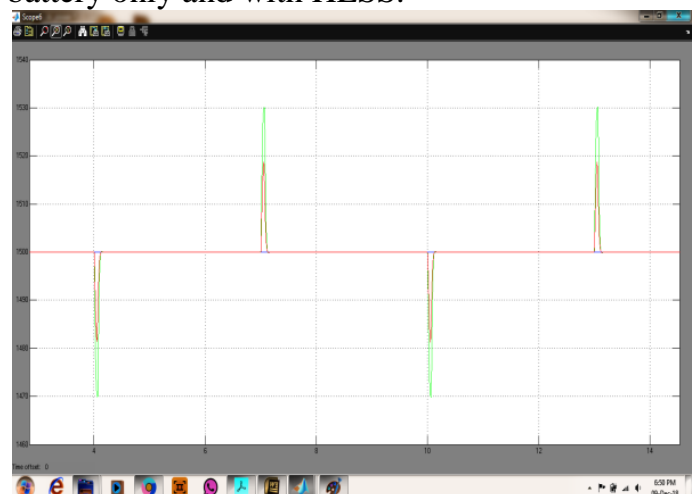

Fig 7: The propulsion motor speed without ESS, with battery-only and with HESS.

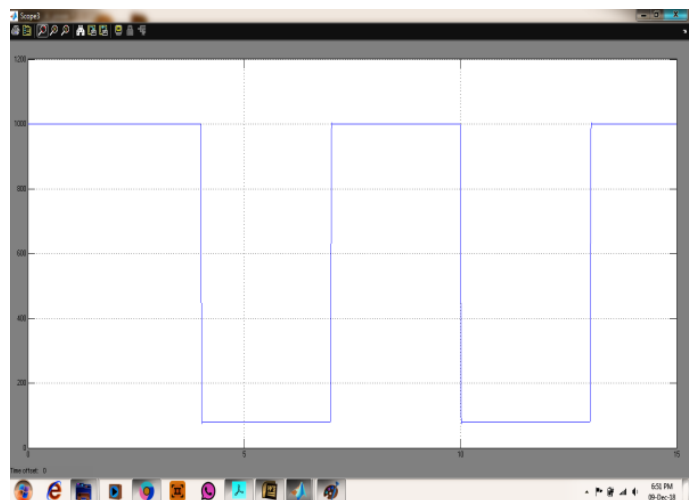

Fig 8: SMES current.

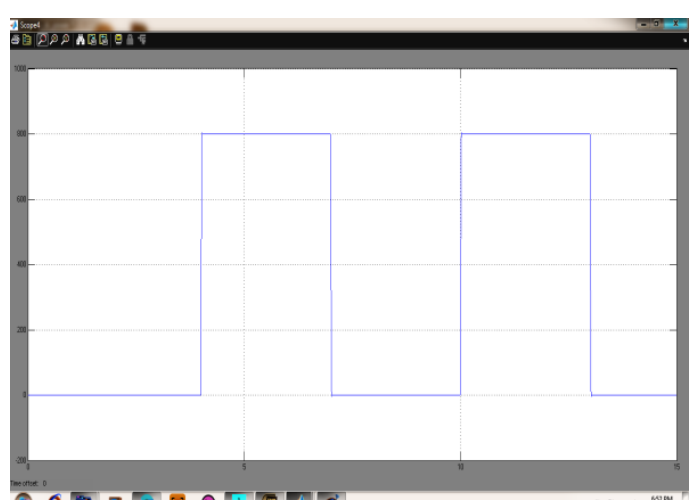

Fig 9: Battery output current.

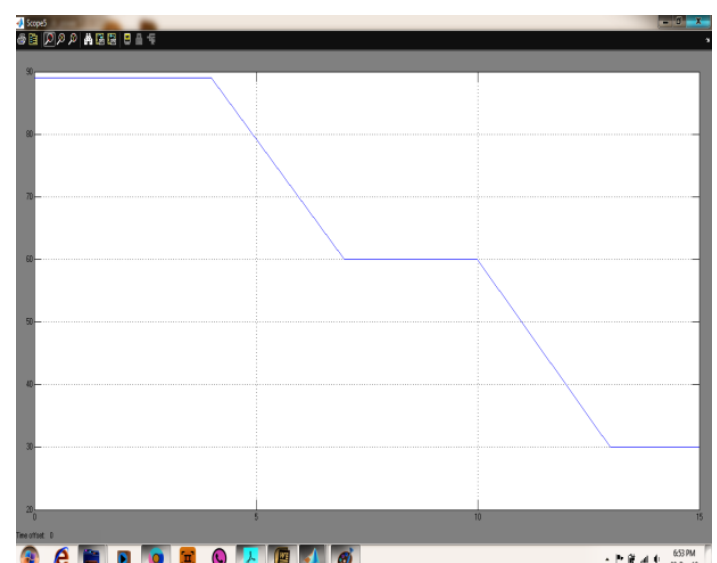

Fig 10: Battery state of charge.

The simulation results demonstrated that the HESS based on the dynamic droop control showed good performance during pulsed load periods, maintaining the main bus voltage at the required range and keeping the motor at the targeted speed. The system was subjected to pulse loads between $\mathrm{t}=4.0-7.0 \mathrm{~s}$ and between $\mathrm{t}=10.0$ $13.0 \mathrm{~s}$. With the HESS, the minimum total generators capacity is $9 \mathrm{MW}$. However, without the HESS the minimum total generators capacity is 14MW. The voltage of the main DC bus was $6 \mathrm{kVDC}$ according to the IEEE standard. In the conditions of without ESS and with battery only, when the pulse load was applied to the system at $\mathrm{t}=4.0 \mathrm{~s}$, the voltage dropped immediately to almost $3 \mathrm{kVDC}$. In the battery-only system, because the battery fed the pulse load, the voltage was regulated to 
the targeted level within a short period. However, in the HESS condition, the voltage remained stable at the targeted level throughout the test, both with and without pulse loads. In contrast, when the pulse load was removed at $\mathrm{t}=7.0 \mathrm{~s}$, the voltage increased rapidly because of the overcurrent. However, at the HESS, because the SMES absorbed the excessive current, the voltage stayed at the targeted level. Figure shows the comparison of the main DC bus voltage without ESS, with batter-only and with HESS. Because the HESS was controlled to supply the pulse loads, the output power of the generators stayed constant at $9 \mathrm{MW}$ with and without the pulse loads, as shown by the red line in Figure shows the motor speed in three different cases: without ESS, With battery only and with HESS. In Figure, the maximum stored current in SMES is $1000 \mathrm{~A}$. When the pulse load is applied to the system, SMES discharges immediately. It discharges $1000 \mathrm{~A}$ in 300 millisecond with a ramp-rate current of $3.3 \mathrm{kA} / \mathrm{s}$. Because the discharge rate is controlled by both Vref and Ismes, the discharge rate is decreased when SMES current decreased. The goal of decreasing the discharge rate of SMES is to slow down the voltage drop in the main DC bus, thus giving more time for the battery to responds. The current and SOC of the battery are shown in Figure, respectively. When the pulse loads are applied to the system, the SMES and the battery discharge to meet the sudden change loads demand at the beginning, then the battery becomes the main source of the power after SMES completely discharged. The current ramp-rate of the battery is $2.6 \mathrm{kA} / \mathrm{s}$ and the constant discharge current is $800 \mathrm{~A}$. In special electrical applications, such as pulse load applications there are a few electrical devices that can supply high power in a short period, such as SMES and batteries. The Lithium-Ion batteries current ramprate can be reduced by increasing the size of SMES. However, a tradeoff between the cost of the SMES and the battery life must be made. In future work, an optimization study will be done to find the optimum battery vs SMES size to have the best price for the ESS and battery life. In this work the main goal is to study the performance of the HESS and the energy storage control method under the sudden load changes.

\section{CONCLUSION}

This project proposes the use of the SMES/battery HESS based on the dynamic droop control in the AES to mitigate the effects of the sudden load changes on the system's stability. The AES including SMES/battery was built in the SimPowerSystems environment to test the system's behavior with and without HESS. The HESS based on dynamic droop control showed good performance during the pulse load periods. By supplying the pulse loads from the HESS, the system maintained the voltage at the targeted level, keeping the motor at the required speed and maintaining constant generation output power both with and without pulse loads.

\section{REFERENCES}

[1] M. Cupelliet al., "Power flow control and network stability in an all electric ship," Proc. IEEE, vol. 103, no. 12, pp. 2355-2380, Dec. 2015.

[2] A.Monti, S. D'Arco, L. Gao, and R. A. Dougal, "Energy storage management as key issue in control of power systems in future all electric ships," in Proc. Int. Symp. Power Electron., Elect. Drives, Autom. Motion, 2008, pp. 580-585.

[3] T. V. Vu, D. Gonsoulin, F. Diaz, C. S. Edrington, and T. El-Mezyani, "Predictive control for energy management in ship power systems under high-power ramp rate loads," IEEE Trans. Energy Convers., vol. 32, no. 2, pp. 788-797, Jun. 2017.

[4] J. Lopez, "Combustion engine vs gas turbine-Ramp rate," Nov. 2016. [Online]. Available: https://www.Wartsila.com

[5] N. H. Doerry and J. V. Amy, "The road to MVDC," in Proc. Intell. Ships Symp., 2015, pp. 1-20.

[6] J. F. Hansen and F. Wendt, "History and state of the art in commercial electric ship propulsion, integrated power systems, and future trends," Proc. IEEE, vol. 103, no. 12, pp. 2229-2242, Dec. 2015.

[7] IEEE Recommended Practice for $1 \mathrm{kV}$ to $35 \mathrm{kV}$ MediumVoltage DC Power Systems on Ships, IEEE Std. 17092010, Nov. 2, 2010, pp. 1-54.

[8] T. Ise, M. Kita, and A. Taguchi, "A hybrid energy storage with a SMES and secondary battery," IEEE Trans. Appl. Supercond., vol. 15, no. 2, pp. 1915-1918, Jun. 2005.

[9] L. Trevisani, A. Morandi, F. Negrini, P. L. Ribani, and M. Fabbri, "Cryogenic fuel-cooled SMES for hybrid vehicle application,” IEEE Trans.Appl. Supercond., vol. 19, no. 3, pp. 2008-2011, Jun. 2009.

[10] A. Cansizet al., "Integration of a SMES-battery-based hybrid energy storage system into microgrids," J. Supercond. Novel Magn., pp. 1-9, 2017. [Online]. Available: https://link.springer.com/journal/ 10948/online First/page/11

[11] C. R. Lashway, A. T. Elsayed, and O. A. Mohammed, "Hybrid energy storage management in ship power systems with multiple pulsed loads," Elect. Power Syst. Res., vol. 141, pp. 50-62, 2016.

[12] M. M. S. Khan,M. O. Faruque, and A. Newaz, "Fuzzy logic based energy storage management system for MVDC power system of all electric ship," IEEE Trans. Energy Convers., vol. 32, no. 2, pp. 798-809, Jun. 2017.

[13] S. Kulkarni and S. Santoso, "Impact of pulse loads on electric ship power system: With and without flywheel energy storage systems," in Proc. 2009IEEE Elect. Ship Technol. Symp., Baltimore, MD, USA, 2009, pp. 568-573.

[14] T. M. I. Mahliaet al., "A review of available methods and development on energy storage; technology update," Renewable Sustain. Energy Rev., vol. 33, pp. 532-545, 2014.

[15] J. Li et al., "Design/test of a hybrid energy storage system for primary frequency control using a dynamic droop method in an isolated microgrid power system," Appl. Energy, vol. 201, pp. 257-269, 2017. 